\title{
Trends of Colorectal Cancer Prevalence in Kazakhstan Related to Screening
}

\author{
Alma Zhylkaidarova', Dilyara Kaidarova', Kanat Batyrbekov' ${ }^{2}$, Oxana Shatkovskaya ${ }^{1}$ and Dinara Begimbetova ${ }^{3}$ \\ ${ }^{1}$ Kazakh Institute of Oncology and Radiology, Almaty, ${ }^{2}$ National Research Oncology Center, Nur-Sultan, ${ }^{3}$ Center for Life Sciences, \\ National Laboratory Astana, Nazarbayev University, Nur-Sultan, Kazakhstan
}

We carried out an analysis of the total incidence of colon cancer throughout Kazakhstan. Retrospectively, according to the regional reports on endoscopic screening, the study showed an increase in the age-related incidence of colorectal cancer (CRC) cases from 2004-2008 to 2009-2014. The peak of morbidity in both periods was noted in the age category of $>70$ years. The indicators of the territorial distribution of CRC incidence make it possible to divide the regions into areas with low or high rates of CRC. Specific indicators showed newly diagnosed cases of CRC stages I, II, III, and IV in 2004-2018. The incidence rates of stages I and II showed a two-fold increase (35\%-67.4\%) and the incidence of stage IV showed a decline from $19.3 \%$ to $13.1 \%$ and of stage III from $45.7 \%$ to $19.5 \%$ from 2004 to 2018, respectively. An analysis of CRC incidence throughout Kazakhstan showed an increase in the overall incidence. Since population-based CRC screening was introduced in 2011, the morbidity was found to increase for stages I and II. Clin Endosc 2021;54:32-37

Key Words: Colonoscopy; Colorectal cancer; Hemoccult test; Kazakhstan; Screening

\section{INTRODUCTION}

Colorectal cancer (CRC) is one of the global health problems and is the third leading cause of morbidity and second leading cause of mortality from cancer worldwide. ${ }^{1,2}$ In the United States and European countries, the incidence is in the range of 20-40 per 100,000 population. In Asian countries, it varies widely (4.4 in India; 44.5 in Korea per 100,000). ${ }^{1}$ In one study that conducted CRC screening in one of the regions of Kazakhstan, ${ }^{3}$ the high number of CRC cases detected indicated the need for more screening programs. An increase in the incidence rate of this pathology was observed since 2011, with the introduction of CRC screening; stage-related data indicate

Received: October 12, 2019 Revised: January 31, 2020

Accepted: February 13, 2020

Correspondence: Kanat Batyrbekov

National Research Oncology Center, Nur-Sultan, Kerey, Zhanibek Khandar St 3, Nur-Sultan 010000, Kazakhstan

Tel: +7-707-474-4980, E-mail: dr.kanat77@gmail.com

ORCID: https://orcid.org/0000-0003-4837-0775

(c) This is an Open Access article distributed under the terms of the Creative Commons Attribution Non-Commercial License (http://creativecommons.org/ licenses/by-nc/3.0) which permits unrestricted non-commercial use, distribution, and reproduction in any medium, provided the original work is properly cited. the predominance of stages I and II.

Attention needs to be given to the "morbidity and mortality" rates, which indicates the level of the development of oncological services in a particular country. In developed countries with a high level of medical care, the mortality rate varies from $24.0 \%$, in Korea, to $37.3 \%$, in Sweden, indicating low mortality, which is an indicator of developed oncological services. ${ }^{1,2}$ In developing countries, this figure ranges from $57.1 \%$, in Kazakhstan, to $75.4 \%$, in India, which indicates a rather high mortality rate and a low level of development of oncological services. $^{2,4}$

Modern colonoscopy must be carried out to diagnose precancerous changes and early forms of cancer. The use of modern diagnosis techniques allows the detection of pathological formations of even the smallest size, such as chromoscopy and narrow-spectrum, magnifying, and autofluorescent endoscopy. The clinical application of these diagnostic methods and detailed visualization of minor pathological changes in the large intestine are possible with methodic studies. An essential condition for ensuring the effective use of endoscopic techniques and improving the quality of colonoscopy is the routine use of modern diagnostic algorithms, which can improve diagnostic results and popularity of endoscopic examination. 


\section{SCREENING PROGRAM OF COLORECTAL CANCER IN KAZAKHSTAN}

According to regional endoscopic screening reports, a retrospective analysis was conducted of the overall incidence of CRC in the regions of Kazakhstan from 2004 to 2018 among people aged 50-70 years. Colorectal screening was implemented in Kazakhstan since the second half of 2011. Screening for CRC in Kazakhstan occurs in two stages, the first stage is a hemoccult test, and if the results are positive, the next step is total colonoscopy. The early stage of detection is carried out by specialized medical care centers (city and district polyclinics). Patients aged 50-70 years, of both sexes, are subject to screening. In the city and district clinics, there are screening rooms that keep records of indicators, and local nurses and doctors examine the patients. In each regional oncologic center, there is a screening room that monitors the screening process and keeps a general record of the identified cases of CRC.

Furthermore, the Kazakh Institute of Oncology and Radiology is developing an improved cancer screening program to identify, record, and analyze cases of cancer. ${ }^{5}$ The annual coverage of the studies ranges from 982,919 (as recorded in 2011) to $1,155,174$ (as recorded in 2012) of both men and women aged $50,52,54,56,58,60,62,64,66,68$, and 70 years. The planned optimal coverage is $70 \%$ of the population according to the register of the assigned population. In 2018, this coverage was $64.4 \%$. The number of CRC cases detected increased from 199 ( $\mathrm{min}$ ) in 2011 to 514 ( $\max$ ) in 2014, and in the last year, 309 cases were detected. Further, the level of detectability increased from $0.02 \%$ to $0.05 \%$, which indicates an increase in the effectiveness of testing. In the last four years, cases of early forms of cancer increased up to $88.3 \%$ in $2018 .{ }^{5}$ The Kazakh Institute of Radiology and Oncology published a statement of endoscopic screening for CRC. The annual report revealed that cancer was detected by regional oncologic dispensaries and the patients were then transferred to the Kazakh Institute of Radiology and Oncology. A summary of the annual report was published by the Agency of Statistics and the Ministry of Health of Kazakhstan. In all regions of Kazakhstan, screening rooms were set up for the survey. The surveyed population was stratified by age and the presence of occult blood in feces. For residents of Kazakhstan, screening for CRC and removal of polyps during screening colonoscopy is part of the medical care for citizens. Screening studies are conducted only in public clinics, not private. According to the order of the Minister of Health of the Republic of Kazakhstan, dated December 25, 2017, № 995, “On approval of the rules of preventive medical examinations of the target population", endoscopists during screening colonoscopy are obliged to simultaneously remove all neoplasms of 0-Ip and 0-Is types according to the Paris classification, measuring up to $0.5 \mathrm{~cm}$. ${ }^{6}$ Currently, cold snare, polypectomy, and endoscopic mucosal resection are prevalent technologies. The endoscopic submucosal dissection technology is available in very few clinics throughout the country, as this technology is costly and the practitioners have insufficient level of skills for its implementation. After starting of the screening program, the endoscopic equipment used in the field was analyzed in 2014. Karl Storz's endoscopic processors were purchased with the support of the Storz Professional Image Enhancement System using state funding.

\section{INCIDENCE OF COLORECTAL CANCER IN OECD COUNTRIES AND KAZAKHSTAN}

Fig. 1. shows that, according to Globocan (2018), the incidence of CRC in Organization for Economic Cooperation and Development (OECD) countries ranges from 11.2\%, in Mexi-

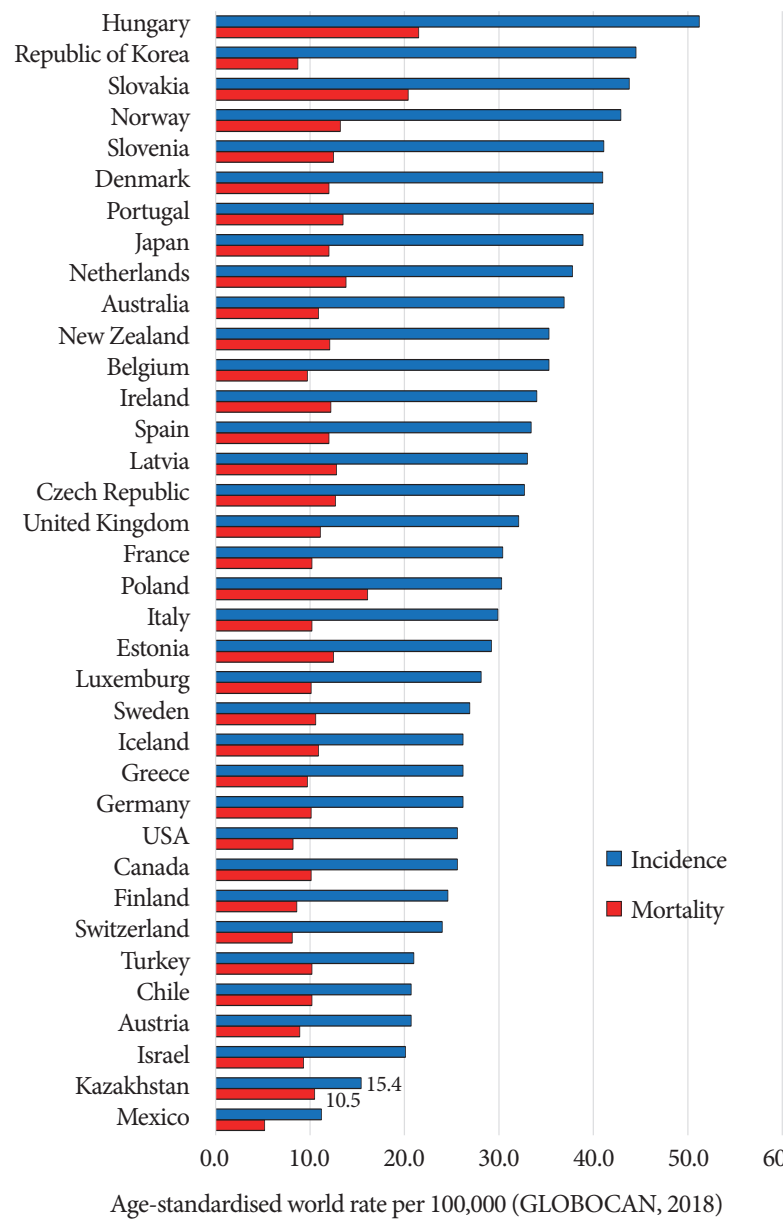

Fig. 1. The incidence and mortality of colorectal cancer in Organization for Economic Cooperation and Development countries and Kazakhstan. 


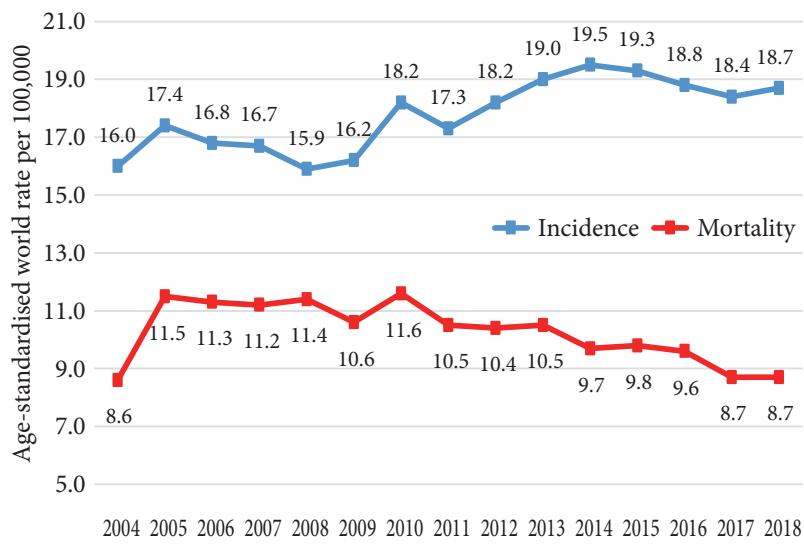

Fig. 2. Dynamics of World Health Organization world standardized indicators of incidence and mortality from colorectal cancer per 100,000 population of Kazakhstan for the period 2004-2018.

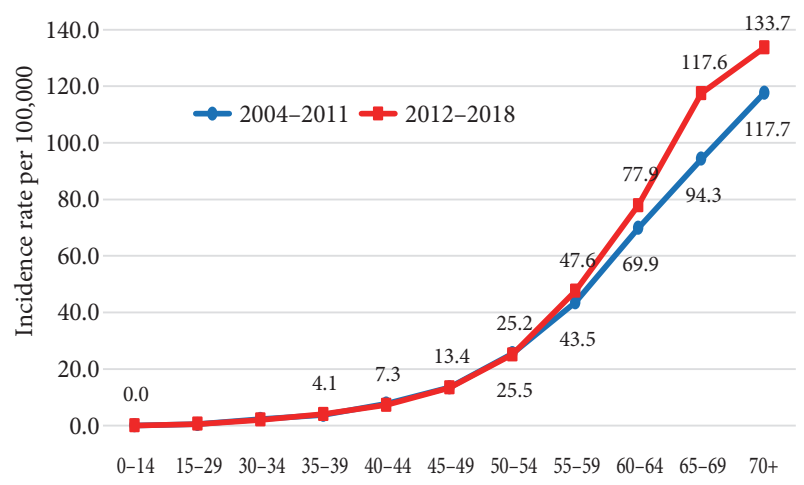

Fig. 3. Age indicators of the incidence of colorectal cancer in Kazakhstan (average per 100,000 inhabitants of the corresponding age for 2004-2011 and 2012-2018).

co, to $51.2 \%$, in Hungary. Mortality from CRC in most OECD countries is in the range of $9 \%-11 \%$, except Hungary and Slovakia, where along with high morbidity, high mortality of up to $20 \%-21.5 \%$ is reported. Low mortality rates were reported in Switzerland (8.1\%), the United States (8.2\%), the Republic of Korea (8.7\%), and Mexico (5.2\%). In terms of morbidity, Kazakhstan ranks almost last among OECD countries (15.4\%). The ratio of mortality-to-morbidity of CRC in the Kazakhstan is $68.2 \%$ - the highest ratio for any OECD countryfollowed by Poland (53.1\%), with the lowest ratio reported in Korea (19.6\%); further, the ratio is $32 \%-33.8 \%$ in the US and Switzerland, $42 \%$ in Hungary, and $46.4 \%$ in Mexico. These statistics indicate the importance of CRC screening within Kazakhstan to detect early stages of cancer and reduce mortality.

Fig. 2. shows the 15-year trend in morbidity and mortality from CRC. In the pre-screening period (2004-2010), there

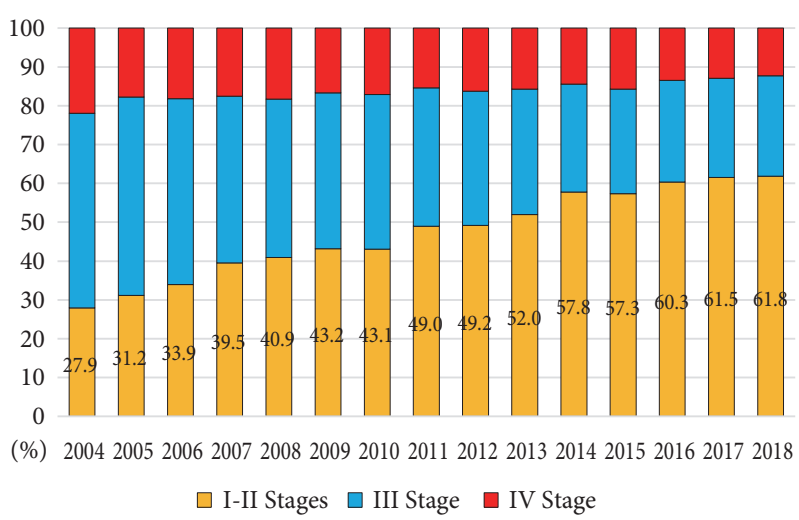

Fig. 4. Proportion of I-II, III , IV stages of primary cases of colorectal cancer in Kazakhstan (\%).

were unstable indicators, with drastic growth and decline. Once the screening program was started, there was an increase in the cases of CRC (2011-2014) with a further decrease and stabilization in the morbidity at $18.7 \%$ in 2018 . The mortality curve in the pre-screening period was stable at the level of $11.2 \%-11.5 \%$. After the introduction of screening, there was a moderate but steady decline in mortality to 8.7 per 100 thousand population. The probability of CRC increased after the age of 40 years and sharply increased after 50 years in both screening (2004-2008) and post-screening (2012-2018) periods. The peak incidence in both periods was noted at the age of over 70 years; the incidence rate at the age of 65-69 years increased from $94.3 \%$ to $117.6 \%$ and at the age of over 70 years from $117.7 \%$ to $133.7 \%$ (Fig. 3), respectively. With the introduction of screening, there has been a steady increase in the proportion of localized cancers (stage II) due to the reduction of locally advanced cases (stage III). Particularly noticeable growth in the early stages (from $49 \%$ to $57 \%-60 \%$ ) occurred since 2014 when the efficiency indicators of screening colonoscopy were introduced (Fig. 4).

\section{TERRITORIAL FEATURES OF COLORECTAL CANCER IN KAZAKHSTAN}

In Kazakhstan, the incidence of CRC shows territorial features. The territory of Kazakhstan is vast (Kazakhstan is the ninth largest country in the world), so there are geographical, economic, and cultural differences between the northern, western, and southern regions. According to the levels of morbidity (average annual rate for 2004-2010), the regions of the country are divided into three groups: high (17\%-26\%), mid (11.7\%-14.1\%), and low (7.4\%-9.0\%) rate. The northern, 


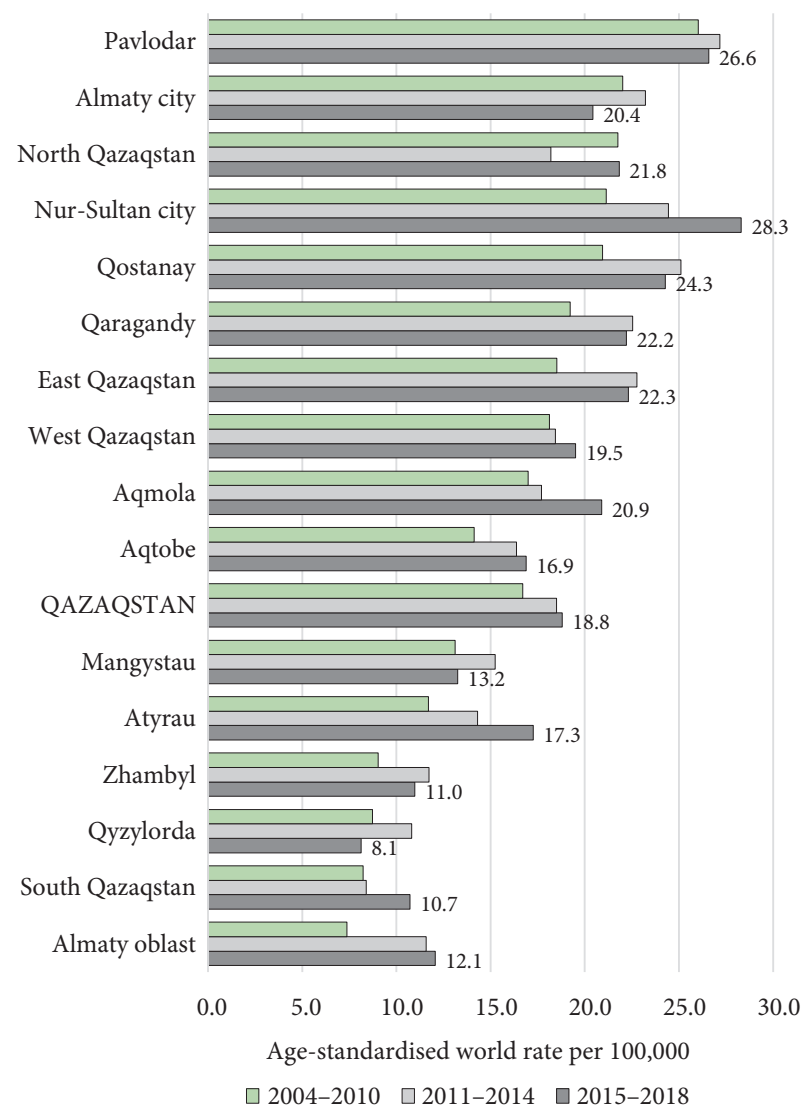

Fig. 5. Territorial incidence rates of colorectal cancer in Kazakhstan (standardized World Health Organization world rates per 100,000 population, 2004-2010, 2011-2014 and 2015-2018).

eastern, and central regions are classified under high rate. In these areas of Kazakhstan, red meat is consumed often, with similar food items/preparations, e.g., in Pavlodar, North Kazakhstan, Qostanay, Akmola region, Qaraghandy, East Kazakhstan, Nur-Sultan, West Kazakhstan, and Almaty (South region). Western Kazakhstan (Aktobe, Mangystau, Atyrau) showed an incidence in the mid-range; in this area, meat and fish are consumed often. Low rate was noted in the southern regions where vegetables and fruits are the traditional foods. The average annual morbidity in the region of Pavlodar (first rank) was 3.5 times higher than that in the region of Almaty (last rank among the territories). The figure shows the average annual levels of morbidity in the first (organizational) stage of the screening (2011-2014) and in the stage of improving the quality of screening (2015-2018) with the introduction of quality indicators of colonoscopy (Fig. 5). In the country, CRC incidence in the first stage of screening increased from
$16.7 \%$ to $18.5 \%$ and then to $18.8 \%$. The increase in morbidity was different in different regions. Effective screening was a factor resulting in an increase in the incidence of CRC. Table 1 compares the detection of cancer in the testing stages and the increase in the rate of CRC during the period of screening implementation in the regions of Kazakhstan. There was noted the influence of screening on the dynamics epidemiological indicators of CRC. One hundred twenty-three indicators of $\mathrm{CRC}$ were assessed using a six-point scale, where 0 denoted no influence of screening, 5 denoted strong impact (Table 1).

In Almaty and North Kazakhstan, high morbidity was reported with the introduction of CRC screening. Of note, in the group of high-morbidity regions, there were regions with stable and positive influence of screening (Nur-Sultan, East Kazakhstan, Qostanay, Qaragandy) as well as regions with low or insignificant influence. In contrast, of the four regions with low baseline morbidity, three showed a pronounced and robust impact of screening on the increase in morbidity; however, the detection rate was the same or lower than that in the country. On the other hand, the country-wide detection rate of CRC ( $0.04 \%$ of coverage) was high. ${ }^{5}$ The surveyed population was the minimum in 2015 , i.e., 791,904 people, and was the maximum in 2012, i.e., 1,174,155 people. Patients with positive hemoccult test results accounted for $1 \%-4 \%$ of the total number of examined patients. The number of screening colonoscopies was the lowest in $2012(33 \%)$ and the highest in 2014 , equivalent to $81 \%$ of the total number of positive hemoccult test results (Table 1). There was a large number of patients with positive results on the hemoccult test during the introduction of the program, which can be explained by improper examination and the presence of false-positive results. There was also a discrepancy between the number of positive hemoccult test results and the number of screening colonoscopies, mainly because a large number of patients refused to undergo colonoscopy because it is performed without sedation. Unfortunately, the quality of screening is not equal to that in developed countries. The differences are due to the lack of advanced equipment, lack of trained personnel, and unavailability of resources for colonoscopy. Furthermore, the population is not informed about endoscopic procedures. In our opinion, the positive impact of screening depends on the quality of screening colonoscopy, the skills of the doctor, and quality of endoscopic equipment used. Unfortunately, some clinics still use fiber endoscopes although video endoscopes are being provided with the support of narrow band imaging (NBI). Further, not all doctors conduct total colonoscopy due to lack of training. 
Table 1. Comparison of Cancer Detection in Screening and Indicators of Increase in the Incidence of Colorectal Cancer during the Implementation of Screening in the Regions of Kazakhstan

\begin{tabular}{|c|c|c|c|}
\hline & $\begin{array}{l}\text { Growth in the incidence rate } \\
\text { over screening period, } \%\end{array}$ & $\begin{array}{l}\text { Cancer detection average rate, \% } \\
(2011-2018)\end{array}$ & $\begin{array}{l}\text { Evaluation of screening impact } \\
\text { from } 0 \text { (absence) to } 5 \text { (strong) }\end{array}$ \\
\hline \multicolumn{4}{|c|}{ Regions with the high background CRC incidence rate } \\
\hline Pavlodar & 3.3 & 0.07 & 1 \\
\hline Almaty & -0.9 & 0.03 & 0 \\
\hline North Kazakhstan & -8.0 & 0.06 & 0 \\
\hline Nur-Sultan & 24.8 & 0.05 & 5 \\
\hline Qostanay & 17.9 & 0.08 & 4 \\
\hline Qaragandy & 16.4 & 0.05 & 4 \\
\hline East Kazakhstan & 21.7 & 0.04 & 5 \\
\hline West Kazakhstan & 4.8 & 0.07 & 1 \\
\hline Aqmola region & 13.5 & 0.03 & 3 \\
\hline \multicolumn{4}{|c|}{ Regions with the middle background CRC incidence rate } \\
\hline Aqtobe & 17.7 & 0.03 & 4 \\
\hline Kazakhstan & 11.7 & 0.04 & 3 \\
\hline Mangystau & 8.6 & 0.03 & 2 \\
\hline Atyrau & 34.8 & 0.03 & 5 \\
\hline \multicolumn{4}{|c|}{ Regions with the low background CRC incidence rate } \\
\hline Zhambyl & 25.7 & 0.04 & 5 \\
\hline Qyzylorda & 8.5 & 0.04 & 2 \\
\hline South Kazakhstan & 16.1 & 0.01 & 4 \\
\hline Almaty region & 60.1 & 0.04 & 5 \\
\hline
\end{tabular}

CRC, colorectal cancer.

\section{CONCLUSIONS}

The result of the analysis shows an increase in the rate of CRC in Kazakhstan. The stage-by-stage distribution of morbidity indicates an increase in stages I and II since 2011. Since the introduction of screening, the incidence of CRC has grown. This growth indicates the positive result of CRC screening, which is associated with positive economic effects as the treatment of stages I and II is cheaper than that of stages III and IV. In addition, a decrease in the total number of primary CRC cases is the result of timely detection of precancerous bowel disease during screening colonoscopy and subsequent treatment. In our opinion, the launch of the national CRC screening program has had a positive effect not only on the health of the population but also on the quality of medical services, e.g., improved equipment, introduction of new methods of diagnosis and treatment, and increased professionalism of doctors. Last year, the national screening program was reviewed by World Health Organization experts, and they recommended further improvements. Currently, the plan is to supply endoscopic equipment, with the support of NBI Equipment, to all regional and state hospitals and oncology centers.

Conflicts of Interest

Kanat Batyrbekov has been an Editorial Board member of Clinical Endoscopy; however, he was not involved in the peer reviewer selection, evaluation, or decision process of this article. The other authors have no potential conflicts of interest.

Funding

None.

Author Contributions

Conceptualization: Dilyara Kaidarova

Data curation: Alma Zhylkaidarova

Investigation: AZ

Methodology: AZ

Resources: Kanat Batyrbekov

Supervision: Oxana Shatkovskaya

Validation: Dinara Begimbetova

Writing-review\&editing: KB 
ORCID

Alma Zhylkaidarova:

Dilyara Kaidarova:

Kanat Batyrbekov:

Oxana Shatkovskaya:

Dinara Begimbetova: https://orcid.org/0000-0003-2050-8672

https://orcid.org/0000-0002-0969-5983

https://orcid.org/0000-0003-4837-0775

https://orcid.org/0000-0001-6085-2780

https://orcid.org/0000-0002-0643-6257

\section{REFERENCES}

1. Bray F, Ferlay J, Soerjomataram I, Siegel RL, Torre LA, Jemal A. Global cancer statistics 2018: GLOBOCAN estimates of incidence and mortality worldwide for 36 cancers in 185 countries. CA Cancer J Clin 2018;68:394-424.

2. Ferlay J, Colombet M, Soerjomataram I, et al. Estimating the global can-

cer incidence and mortality in 2018: GLOBOCAN sources and methods. Int J Cancer 2019;144:1941-1953.

3. Abdullayev MS, Nurgaziev KS, Zhylkaydarova AZ, Mansurova AB. Epidemiological aspects of colorectal cancer in Kazakhstan. Surgery News 2017;25:394-403.

4. Batyrbekov KU. [Some aspects of endoscopic colorectal cancer screening in Kazakhstan]. Avicenna Bulletin 2016;3:38-41.

5. Kaidarova DR, Zhylkaidarova AZH, Akhetov AA, Shanazarov NA, Batyrbekov KU. [Change of epidemiological situation of colorectal cancer in Kazakhstan after introduction of screening]. Avicenna Bulletin 2018;2-3:157-165.

6. Order of the minister of health of the Republic of Kazakhstan dated December № 995 "On approval of the rules of preventive medical examinations of the target population" [Internet]. Almaty: Ministry of Justice of the Republic of Kazakhstan; c2017 [updated 2017 Dec 25; cited 2019 Aug 24]. Available from: http://adilet.zan.kz/rus/docs/V1700016223\#z6. 